\title{
Desafios e experiências do ensino superior no interior do Brasil: a implantação do curso de História em Porto Nacional, Tocantins
}

\author{
Challenges and experiences of higher education \\ in inland Brazil: the implementation of the History \\ course in Porto Nacional, Tocantins
}

Roniglese Pereira de Carvalho Tito*

\section{RESUMo}

$\mathrm{O}$ artigo discute a institucionalização do ensino superior de História no antigo norte de Goiás, região que atualmente corresponde ao estado do Tocantins. O texto aborda as motivações que levaram o governo estadual a promulgar a lei de criação da Faculdade de Filosofia do Norte Goiano (Fafing), no início dos anos 1960; os episódios que adiaram a sua implantação durante o Regime Militar; a política de interiorização do ensino superior em Goiás, que culminaram com a autorização de funcionamento dessa Faculdade, na década de 1980; e as transformações ocorridas após a sua encampação pela Universidade do Tocantins, no início da década de 1990. Na segunda parte aborda-se a estruturação do curso superior de História, marcada pelas definições/redefinições do currículo e pelas constantes reformulações do corpo docente.

Palavras-chave: ensino superior de História; profissionalização docente; currículo.

\section{Abstract}

The article discusses the institutionalization of History higher education in the old northern Goiás region, which currently corresponds to the state of Tocantins. This paper addresses the motivations that led the state government to promulgate a law creating the Faculdade de Filosofia do Norte Goiano (Fafing), in early 1960s; the episodes that have delayed its implementation during the military regime; the internalization of higher education policy in Goiás, which culminated with the license to operate this college, in the 1980s; and the changes which took place after its takeover by the Universidade do Tocantins, in the early 1990s. The second part deals with the structuring of the History higher education course, marked by the definitions / redefinitions of the curriculum and the constant reformulation of the faculty.

Keywords: History higher education; teacher's professionalization; curriculum.

\footnotetext{
* Supervisor de Pesquisas do Instituto Brasileiro de Geografia e Estatística (IBGE). Quadra 108 Norte, Alameda 04, Lote 38, Centro. 77006-100 Palmas - TO - Brasil. roniglese.tito@ibge.gov.br
} 
Estabeleceu-se, nas últimas décadas, uma área de produção sobre o ensino de História no âmbito do ensino superior, com trabalhos relacionados ao currículo, ao livro didático, à formação profissional e à criação de cursos, Faculdades e Universidades. No que se refere aos estudos que contemplam a institucionalização dos cursos de História, em particular, a análise das temáticas abordadas, bem como dos caminhos e argumentos utilizados pelos pesquisadores, evidencia que as pesquisas têm procurado conciliar a análise dos processos de ensino e os elementos que compreendem a formação e conformação das características que permeiam a questão da formação do profissional da área: contextos políticos, trajetória acadêmica dos professores, concepções de história e legislação educacional, entre outras.

Nesse viés, por exemplo, situa-se a pesquisa empreendida por Marieta de Moraes Ferreira sobre a institucionalização do curso de História junto à Universidade do Distrito Federal (UDF), criada no Rio de Janeiro, na década de 1920. Em síntese, a autora associa trajetória e perfil dos professores ao contexto sociopolítico e educacional da época para problematizar as questões que envolviam as disputas político-educacionais, a concepção de história que norteou o curso em diferentes momentos, e as tentativas de conciliar formação pedagógica - privilegiando a formação de professores - e a preocupação em oferecer aos futuros mestres conhecimentos voltados para a pesquisa. ${ }^{1}$

A perspectiva analítica adotada por Ferreira está presente também, em grande medida, na pesquisa realizada por Diogo da Silva Roiz sobre o curso de História da Faculdade de Filosofia, Ciências e Letras da Universidade de São Paulo, entre 1934 e $1956 .{ }^{2}$ Roiz buscou verificar como professores historiadores, brasileiros e franceses, que fizeram parte do corpo docente inicialmente contratado para as atividades de docência e de pesquisa, atuaram na delimitação do quadro curricular e nas suas redefinições, as quais foram ocorrendo com a incorporação de uma nova geração de professores ao longo dos anos. Uma constatação assinalada por Roiz está no que denomina de 'barreiras técnicas e administrativas' no processo de institucionalização do curso de História da USP. Ao analisar as propostas de reformulações curriculares, o pesquisador evidenciou que as dificuldades encontradas pelos professores eram maiores do ponto de vista administrativo e não do teórico. Isso porque a Faculdade Nacional de Filosofia, órgão responsável, a partir dos anos 1940, pela padronização do currículo de todas as faculdades de filosofia do país, 
impunha verdadeiras barreiras à autonomia acadêmica, interferindo de forma significativa no que se deveria ensinar nessas faculdades.

Algumas das tensões evidenciadas por Ferreira e por Roiz também são captadas por Mara Cristina de Matos Rodrigues em sua pesquisa sobre A institucionalização da formação superior em história: o curso de Geografia e História da UPA/URGS - 1943 a 1950. A autora levanta hipóteses de trabalho para o contexto em que a Universidade esteve sob a gestão do governo do estado, "profundamente sujeita às interferências da política partidária e da correlação de forças dos grupos intelectuais locais”. Durante aquele período, os professores tinham contratos provisórios ou eram interinos nas cátedras, e as decisões internas na universidade estavam menos sujeitas às regras estabelecidas nacionalmente pela legislação federal. Entre os pontos relevantes assinalados por Rodrigues está a definição dos critérios utilizados para essa contratação dos docentes. De acordo com suas análises, requisitos como a experiência didática prévia em disciplinas idênticas ou próximas à que seria assumida nos cursos de Geografia e História eram observados somente em relação aos catedráticos, ao passo que a seleção dos professores assistentes se dava quase que exclusivamente com base na indicação pessoal do docente responsável pela cátedra.

Verifica-se, portanto, nessas três pesquisas realizadas em temporalidades semelhantes (décadas de 1930 e 1940), mas em contextos diferentes, uma gama de problemáticas em relação à institucionalização dos cursos superiores de História no Brasil que, com efeito, dão origem a diversas possibilidades analíticas: a concepção de história e a filiação teórica que permearam a implantação desses cursos; o dilema entre docência e pesquisa durante a formação profissional e as tentativas de conciliação; as associações entre ensino de história e a conjuntura sociopolítica local e nacional; a relação quase sempre conflituosa entre as proposições docentes em torno do currículo e o que preconizavam os organismos responsáveis pela normatização dos cursos; e a constituição do corpo docente, no que se refere ao perfil e aos critérios de seleção, entre outras.

Diante desse quadro, acredita-se que o alargamento dos estudos sobre o tema pode contribuir para identificar e compreender as configurações tomadas pelos cursos de História segundo as fases de urbanização e desenvolvimento econômico e o consequente processo de expansão do ensino superior pelo interior do país. É precisamente nesse ponto que este artigo se insere, ao 
estabelecer como objeto o processo de institucionalização do curso superior de História na cidade de Porto Nacional, cidade do antigo Norte Goiano, hoje estado do Tocantins. O período de abrangência retroage ao ano de 1963, quando o governo do estado de Goiás criou em lei o referido curso, para funcionar junto à Faculdade de Filosofia do Norte Goiano, e se estende até o momento de sua encampação pela Universidade Federal do Tocantins, em 2002.

\section{DA CONCEPÇÃO À EFETIVAÇÃO DO ENSINO SUPERIOR de História no Norte Goiano}

Quem pretende se aproximar do próprio passado soterrado deve agir como um homem que escava. Antes de tudo, não deve temer voltar sempre ao mesmo fato, espalhá-lo como se espalha a terra, revolvê-lo como se revolve o solo. Pois 'fatos' nada são além de camadas que apenas à exploração mais cuidadosa entregam aquilo que recompensa a escavação. ${ }^{3}$

Em consonância com Benjamin, escavemos os 'fatos':

Era uma quarta-feira, 4 de setembro de 1963. O Diário Oficial do estado de Goiás publicava a Lei 4.505, criando a Faculdade de Filosofia do Norte Goiano, na cidade de Porto Nacional. O seu artigo primeiro estabelecia Línguas Modernas, Pedagogia, Matemática, Física, Geografia e História como as áreas que deveriam compor o quadro de cursos da instituição. O segundo ressaltava que o Poder Executivo tomaria as medidas necessárias para a implantação da Faculdade, e o terceiro autorizava o provimento das operações de créditos, fazendo constar dotação orçamentária para os anos subsequentes. Assinaram a Lei o então governador, Mauro Borges Teixeira, e o secretário de Educação e Cultura, Ruy Rodrigues da Silva.

Parecia ser a certidão de nascimento do ensino superior de História para atender as demandas de uma porção significativa do centro-norte brasileiro. A iniciativa foi recebida com grande alvoroço e entusiasmo pela população da cidade de Porto Nacional, município localizado a aproximadamente 800 quilômetros de Goiânia ou Brasília. Até então, em razão das distâncias, o acesso de alguém que residisse naquela região a um curso superior exigia alto investimento financeiro, privilégio restrito a algumas poucas famílias mais abastadas. 
Contudo, a Lei 4.505 não sairia do papel naquela época.

Antes de verificar o porquê do adiamento desse projeto político, ideal de professores e sonho de uma população, faz-se necessário retomar alguns pontos importantes do contexto que motivou a promulgação da lei. Novamente invocando a metáfora elaborada por Benjamin, espalhemos os 'fatos' como se revolve a terra, numa tentativa de aproximação a um passado aparentemente soterrado.

Primeiro, cumpre destacar que Goiás vivenciava, naquele início dos anos 1960, uma série de transformações de ordem econômica e social que favoreceram o processo de implantação do ensino superior no estado, especialmente aqueles voltados para a formação docente. As terras goianas começavam a ser vistas como a nova fronteira agrícola do país e um importante celeiro da pecuária nacional. Ao mesmo tempo, essa condição exigia uma infraestrutura que permitisse escoar a produção para os grandes centros consumidores, notadamente os estados das regiões Sul e Sudeste. Também se procuravam formas de integração aos portos, visando à exportação para a Europa, os Estados Unidos e a Ásia: novas estradas foram abertas, rodovias pavimentadas, pontes e aeroportos construídos. Para garantir a execução desse projeto, ao mesmo tempo em que Goiás ganhava evidência no cenário brasileiro, sua máquina estatal demandava o desenvolvimento de estratégias que promovessem a profissionalização do seu corpo técnico-burocrático. Esses aspectos, associados à transferência da Capital Federal (1960), criaram as condições políticas que favoreceram a consolidação do ensino superior na região, com destaque para a Universidade de Brasília (UnB), em 1961, e para a Universidade Federal de Goiás (UFG), um ano antes. Nelas foram implantados cursos para a formação de mão de obra técnica especializada tanto nas áreas de engenharia, medicina e direito, quanto nas áreas humanas e sociais.

Em segundo lugar, é importante também destacar que é nessa atmosfera que, em 1961, Mauro Borges Teixeira assume o governo de Goiás pelo Partido Social Democrático (PSD). Filho do fundador de Goiânia, Pedro Ludovico Teixeira, Mauro Borges se inspirou na administração orientada pelo planejamento de caráter desenvolvimentista colocado em prática por Juscelino Kubitschek. Também incorporou bandeiras das chamadas 'reformas de base' propostas pelos movimentos sociais desde a década anterior: a reforma agrária, 
a universalização dos serviços de saúde e a erradicação do analfabetismo por meio da educação popular, entre outras.

Para compor seu grupo de Assessoramento Direto na Secretaria Estadual de Educação, Mauro Borges convidou o ex-padre Ruy Rodrigues da Silva, educador influenciado pelo pensamento de importantes intelectuais da sua época, como se percebe em seus livros de memórias que revelam, em prosa e verso, a síntese dos seus ideais de educação, em grande medida coerentes com os de um dos seus grandes inspiradores, Paulo Freire: "A minha filosofia sempre foi a de que não basta você ler o mundo, conhecer o mundo ... Você tem que ter capacidade de transformar esse mundo", escreveu em certo momento. ${ }^{4}$

Considerado profundo conhecedor da realidade educacional de Goiás, ao assumir a pasta, em 1962, Ruy Rodrigues qualificou de 'quantitativamente insuficiente' e 'pedagogicamente desastroso' o sistema de ensino:

a situação do ensino elementar em Goiás era de uma precariedade horrível. Basta julgar pelo seguinte: de 450 mil crianças na idade de escolarização, apenas 162 mil se achavam inscritas em escolas públicas e privadas, sob o regime multisseriado. Apenas 5\% dessas crianças chegavam ao quarto ano da escolaridade obrigatória. Dentre os professores, $73 \%$ não tinham cursado sequer a escola normal e nem recebido uma formação pedagógica adequada. Não era raro encontrar, entre eles, alguns que ignorassem até mesmo os rudimentos da cultura geral, indispensáveis ao exercício da função. Como se admirar, então, que $68 \%$ da população fosse analfabeta? ${ }^{5}$

A falta de qualificação do corpo docente das escolas de ensino básico consistia no principal problema a ser enfrentado pela gestão de Ruy Rodrigues. Nesse aspecto, entre as principais medidas adotadas destacaram-se as iniciativas que podem ser consideradas avançadas para a época, embora os termos não sejam necessariamente os de hoje. Investiu na formação continuada de professores com a criação dos Centros de Aperfeiçoamento de Ensino, que ofereceram capacitação teórica e prática aos profissionais do Magistério, e implantou Delegacias Regionais de Educação e de Cultura que visavam descentralizar as decisões administrativas e pedagógicas, reduzindo as grandes distâncias entre os municípios do interior e a capital. Essa aproximação permitiu a presença frequente dos técnicos da Secretaria nas escolas, com o objetivo de 
orientar e controlar o processo educativo, promover os 'ajustes administrativos' e apoiar a elaboração de planos políticos-pedagógicos. ${ }^{6}$

Graças a essas medidas, Ruy Rodrigues recorda que o ensino teve uma melhoria na qualidade e se expandiu quantitativamente, atingindo as camadas da população até então excluídas. Em termos numéricos, ressalta que:

o balanço de nosso primeiro ano no setor educacional, malgrado todas as limitações, fora positivo e encorajador. Tínhamos construído e equipado cem novas salas de aula; distribuído 8 mil carteiras novas; organizado estágios de aperfeiçoamento para todos os diretores das escolas de primeiro grau do estado; oferecido sessões de reciclagem de 45 dias, durante o verão, em 31 cidades espalhadas nas várias regiões. Dessas ações, conduzidas por mais de 1.500 especialistas, participaram 2.250 professoras não diplomadas. A despeito da realização desse programa, o primeiro executado no Brasil, continuávamos longe do objetivo visado. Basta lembrar que a equipe de pedagogos encarregada do enquadramento dos cursos foi apoiada por técnicos do serviço de higiene e de saúde, de agricultura e de engenharia rural, que faziam exposições relativas às suas áreas respectivas. (Silva, 2009, p.44)

Nessa fala evidencia-se a precariedade da formação docente na região, mesmo com as medidas paliativas adotadas. Segundo Ruy Rodrigues, a carência de professores na época era tão grande que se fazia necessária a adoção de novos modelos de formação inicial, uma vez que as Escolas Normais não estavam conseguindo atender a demanda no estado. Constatava-se que essas Escolas tradicionalmente educavam as jovens de classe média ou rica, as quais não sentiam nenhum atrativo particular pela carreira de magistério, mal remunerada e pouco gratificante. A situação se agravava quando era necessário ensinar em escolas periféricas ou rurais, muitas vezes mal equipadas, como as de Goiás na época.

Diante disso, a Secretaria de Educação decidiu criar o Centro de Formação de Professores, que oferecia uma escolarização em 3 anos, em regime de internato e em nível equivalente ao das Escolas Normais. Os alunos eram bolsistas do estado, mediante o compromisso de ensinar por certo período na rede pública. Durante o curso eram submetidos a orientação psicopedagógica constante, enriquecida por estágios práticos obrigatórios. Esse modelo chegou a qualificar duzentos novos professores por ano. 
Alinhada ao plano de desenvolvimento regional proposto por Mauro Borges, essa experiência foi decisiva para que a Secretaria de Educação de Goiás postulasse a criação de Faculdades estaduais no interior. É precisamente como parte integrante desse projeto político, graças à visão educacional de Ruy Rodrigues da Silva, conhecedor das implicações que a ausência de professores habilitados provocava sobre a baixa qualidade do ensino, e diante da inexistência de instituições de ensino superior naquela região do Brasil, que se promulga a lei de criação da Faculdade de Filosofia do Norte Goiano (Fafing), em 1963, para ser instalada na cidade de Porto Nacional.

Esses são, certamente, alguns dos motivos que levaram à promulgação da Lei 4.505, que deveria ser a certidão de nascimento da formação de professores de História com nível superior naquela região do país.

O impedimento desse nascimento veio em 1964. A implantação da Fafing não ocorreu, inicialmente sob a alegação de que a região não dispunha de profissionais para trabalhar na nova Faculdade. ${ }^{7}$ Ao longo da década, as medidas econômicas adotadas pelo governo federal, que em linhas gerais desobrigavam o Estado do financiamento do ensino, também se constituíram em entrave. A própria Constituição de 1967, ao não vincular a porcentagem de verbas destinadas à educação ao Orçamento Geral da União, possibilitou que, a partir de então, o Estado passasse a diminuir, sucessivamente, os investimentos no setor educacional. ${ }^{8}$

Corroborou para o adiamento, ainda, aquilo que Germano (1993) denomina de "ataque central à formação de professores" durante o Regime Militar. No início de 1969, amparado pelo Ato Institucional no 5, o governo federal, por meio do Decreto-Lei no 547 , autorizou a organização e o funcionamento de cursos profissionais de curta duração, admitindo habilitações intermediárias em nível superior para atender as 'carências do mercado'. Naquele momento, passou-se a considerar desnecessária a formação por meio das licenciaturas plenas, provocando uma acelerada 'desqualificação estratégica' dos professores. É importante registrar, ainda, que a Lei $n^{\circ} 5.692$, de 11 de agosto de 1971, que estabelecia as diretrizes e bases para o ensino básico, reorientou o $2^{\circ}$ grau para a habilitação profissional. Ao dar ênfase à profissionalização técnica em nível médio, as disciplinas das áreas específicas adquiriram centralidade no currículo em detrimento das de formação geral, em especial História, 
Sociologia e Filosofia. Com a redução de horas/aula menos professores foram necessários e, obviamente, menos cursos de formação. ${ }^{9}$

Não se pode desconsiderar a importância dessas medidas referentes ao financiamento da educação e da nova legislação para a formação docente, mas é possível afirmar que a explicação decisiva para a não implantação do ensino superior de História naquele interior do Brasil, à época, é encontrada na conjuntura política e no perfil de parte da equipe técnica do governo de Goiás, em 1964.

Vale lembrar que, mesmo tendo apoiado o Golpe Militar de 31 de março, o então governador de Goiás, Mauro Borges, não demorou a ser acusado de manter um governo com tendências comunistas e subversivas, contrários às orientações da 'Revolução', e por ter participado da chamada Campanha da Legalidade, liderada pelo governador do Rio Grande do Sul Leonel Brizola, que visara garantir a posse de João Goulart, em 1961, após a renúncia de Jânio Quadros. ${ }^{10}$ Em 1964, o governo federal tentou intervir na administração de Goiás com a exigência de que Mauro Borges substituísse três de seus secretários acusados de serem comunistas, entre eles Ruy Rodrigues, o qual compunha um grupo de assessores de Borges considerados promotores de ações contrárias aos militares, principalmente no campo da educação e da reforma agrária. Inicialmente o pedido não foi atendido, o que levou o próprio Mauro Borges a passar por um processo incriminatório com a instauração de um Inquérito Policial Militar (IPM), instrumento largamente utilizado após o Ato Institucional $n^{\circ} 1$. Não obtendo resultado direto com o IPM, a chamada 'linha dura' do regime solicitou ao presidente Castello Branco que depusesse Mauro Borges. Após aprovação na Câmara, foi assinado o Decreto de Intervenção Federal em Goiás, cumprido no dia 26 de novembro de $1964 .{ }^{11}$

Esse movimento que resultou na queda do governador Mauro Borges Teixeira levou à destituição de Ruy Rodrigues do cargo de secretário de Educação, inviabilizando quaisquer de suas proposições. O próprio Ruy afirma que o impacto produzido por suas iniciativas e o eco provocado na imprensa o ajudariam a ganhar preciosos aliados, em âmbito estadual e nacional, entre os quais menciona as figuras de Anísio Teixeira, Paulo de Tarso e Darcy Ribeiro, além do reconhecimento da Unicef.

Mas foi precisamente por sua perspectiva de formar cidadãos críticos, sustentados em processos educacionais formais, que Ruy Rodrigues sofreu aquilo que para ele foi a sua maior derrota, como se observa em outra 
passagem de um dos seus livros: "eu tentei fazer uma revolução no ensino, razão pela qual fui interrogado, caçado e refugiado político" (Silva, 2009, p.44). De fato, no mesmo ano em que deveria ser implantada a Fafing e, consequentemente, começaria a funcionar o primeiro curso superior de História naquela região do país, Ruy Rodrigues sofreria o destino de tantos outros brasileiros que ousaram praticar atividades contrárias à ideologia do regime que se instaurou com a chegada dos militares ao poder: teve de se autoexilar, deixando o país em direção a Europa, disfarçado de secretário de dom Fernando Gomes, bispo brasileiro que participaria de uma das seções do Concílio Vaticano II, em Roma, ainda em 1964. ${ }^{12}$

Apenas no contexto da redemocratização do país, duas décadas depois de sua concepção inicial, o projeto da Fafing ganharia novamente fôlego.

Vale lembrar que a década de 1980 é recorrentemente tratada, no Brasil, como um período de reorientação das políticas para o setor educacional, na direção de um modelo que atendesse a nova ordem do mundo globalizado e competitivo e suas respectivas demandas por qualificações. Também Goiás vivenciava um significativo processo de expansão das Instituições de Ensino Superior, sobretudo na sua parte sul, de maior poder aquisitivo, onde para garantir as estratégias de financiamento, os municípios criaram fundações que, embora públicas, tinham o atributo jurídico de cobrar mensalidades. No discurso de seus dirigentes, as faculdades municipais convertiam-se em mecanismos de desenvolvimento e atração de investimentos, ampliação da oferta de serviços e melhoria da qualidade de vida de sua população. ${ }^{13}$

Paralelamente, a Secretaria de Educação de Goiás pretendia criar três faculdades destinadas à formação de professores na região centro-norte do estado. Duas primeiras foram definidas para implantação nas cidades de Porangatu e Araguaína, o que levou a população de Porto Nacional a exigir a efetivação da Fafing, criada em lei desde 1963. Reativar a nomenclatura Faculdade de Filosofia do Norte Goiano significava a manutenção dos ideais de educação de Ruy Rodrigues, de se ter cursos voltados para a formação de professores na região.

Enquanto o governo estadual se ocupava com os procedimentos legais, a Prefeitura de Porto Nacional deparava com o primeiro grande desafio para a implantação da Faculdade: encontrar uma estrutura física. A missão não era fácil, pois, além das salas de aula para o primeiro ano de funcionamento, seria 
necessário considerar que a proposta previa a realização de vestibulares anuais, exigindo a expansão do espaço para os anos seguintes. O local escolhido foi o Colégio Sagrado Coração de Jesus, que possuía uma tradição de quase um século na área de formação de professores de níveis elementares. Além de um significativo acervo bibliotecário, o Colégio contava com um corpo docente reconhecidamente experiente na formação de profissionais do magistério.

A efetivação se deu em 1985. Uma faixa de tecido com a inscrição "Faculdade de Filosofia do Norte Goiano" simbolizava o caráter de improviso, dificuldades e superação em que o curso de História nasceu. Com duas décadas de atraso, tornava-se possível a realização do primeiro vestibular. Em reportagem do jornal $O$ Estado do Tocantins a manchete destacava: "Fafing se prepara para o seu primeiro vestibular: expectativa da Secretaria de Educação é positiva". Ressaltava, ainda, trechos de entrevista com um dos vestibulandos, o qual afirmava ser 'histórico' aquele momento, pois "os nortistas não precisavam mais ir para Goiânia para ter um diploma de curso superior". ${ }^{14}$

\section{RECURSOS HUMANOS E ORIENTAÇÕES CURRICULARES NA FORMAÇÃO DO PROFISSIONAL DE HISTÓRIA}

Em meados da década de 1980, vivia-se um momento de expectativas para novos rumos do ensino da disciplina e da profissionalização dos historiadores, motivando a realização de eventos nas principais Instituições de Ensino Superior do país. ${ }^{15}$ Nessas oportunidades questionaram-se os conhecimentos escolares, tanto teóricos quanto metodológicos, e exigiu-se a abertura de espaços para a proposição e o debate de reformulações nos currículos educacionais herdados da ditadura, numa tentativa de superá-los.

Esse cenário favorável aos debates e às proposições esteve, contudo, em descompasso com parte da legislação sobre a organização e o funcionamento do ensino superior em vigência, elaborada e instituída ainda sob a orientação das políticas do Regime Militar. É nessa interface que o primeiro vestibular realizado pela Fafing previa o ingresso dos alunos no curso de Estudos Sociais (ES), o qual, segundo a autorização de funcionamento, consistiria em tronco comum de História e Geografia. Por esse modelo, um estudante que desejasse poderia se formar em Estudos Sociais em 2 anos, para lecionar da $1^{\circ}$ à $8^{\text {a }}$ série, ou cursar mais 2 anos, em uma grade curricular complementar de História ou 
Geografia, e obter a titulação de Licenciatura Plena em uma dessas duas áreas de conhecimento.

Cabe lembrar que no final dos anos 1960 e começo dos 1970 ocorreram grandes mudanças na legislação educacional, como a introdução da disciplina de Estudos Sociais e a supressão do ensino de História no currículo do $1^{\circ}$ Grau. ${ }^{16}$ Contudo, apesar da inflexão no mercado de trabalho, os cursos superiores de História continuaram existindo, principalmente nas maiores instituições públicas. Mais ainda, na medida em que os ares da democracia favoreceram a tomada de fôlego, os profissionais e as entidades representativas passaram a lutar pela progressiva retomada do ensino de História na educação primária e secundária. Em consequência disso, as instituições que ofereciam o curso de Estudos Sociais, sobretudo as particulares, não tardaram a propor formas alternativas ao modelo de formação de professores então vigente, solicitando o aproveitamento desse curso como tronco comum para a habilitação em História.

A despeito dessas questões, em termos práticos, a carência de professores historiadores durante os 2 primeiros anos exigiu que a Diretoria da Fafing utilizasse a estratégia de concentrar na primeira parte do currículo o maior número de disciplinas que poderiam ser ministradas por pessoas que possuíam outras habilitações, favorecendo o que preconizava a legislação sobre o currículo mínimo do curso de Estudos Sociais. ${ }^{17}$

Essa característica inicial do curso de História da Fafing trazia dois aspectos positivos. O primeiro consiste na disposição das disciplinas ao longo dos 2 anos voltados para a formação em Estudos Sociais, em que os programas da área pedagógica foram intercalados com os conhecimentos da Geografia e da História. Esse desenho rompia com o tradicional modelo em que a formação em conteúdos específicos se dá em momentos separados das práticas de ensino. ${ }^{18}$ Em termos teóricos, percebe-se que o núcleo básico, que constituiu o tronco comum à História e à Geografia, conferiu unicidade em termos de projeto pedagógico da Faculdade, além de possibilitar que um mesmo professor fosse aproveitado nos dois cursos. Isto poderia favorecer a troca de conhecimentos e a circulação de informações. O segundo aspecto advém de outra situação característica do momento de implantação da Faculdade, pois na medida em que não havia carga horária suficiente para os professores, a maioria deles atuava concomitantemente no ensino superior e no básico. Isso 
poderia contribuir para uma maior aproximação entre o que se ensinava na Faculdade e a realidade que o futuro profissional iria enfrentar na prática.

O curso de licenciatura curta em Estudos Sociais teoricamente poderia favorecer a formação de professores cujos conhecimentos assegurassem a sua 'competência polivalente'. Mas essa estrutura curricular trazia duas questões complicadas. Primeiro, a perspectiva de uma história linear na qual os conteúdos estavam distribuídos em uma única disciplina denominada Elementos de História Antiga, Medieval e Moderna, com 60 horas, e em outra chamada Elementos de História Contemporânea e do Brasil, com 120 horas. Segundo, não havia disciplinas teóricas que promovessem embasamentos em relação aos conteúdos, o que limitava muito em termos de docência, seja na História ou na Geografia, independentemente do nível de escolaridade em que os futuros professores fossem atuar.

Contudo, esse currículo não perduraria por muito tempo na Fafing. A sua alteração esteve associada à superação de algumas dificuldades iniciais enfrentadas pela Faculdade nos seus 2 primeiros anos de funcionamento, sobretudo no que se refere à composição do quadro docente. A partir de 1987 começaram a chegar a Porto Nacional professores com formação específica em História, ainda que apenas em nível de graduação, permitindo que a direção solicitasse junto ao Conselho Estadual de Educação de Goiás modificações na Estrutura Curricular do curso de História, eliminando a opção de formação em Licenciatura curta em Estudos Sociais. $\mathrm{O}$ atendimento ao pleito veio por meio da Resolução $n^{\circ} 217$, que autorizou também mudanças nas disciplinas que antes compunham a parte diversificada.

A nova Estrutura estava em consonância com o currículo dos cursos de História em nível nacional, no qual os 2 primeiros anos eram reservados às disciplinas dos conhecimentos específicos e os últimos anos eram destinados quase que exclusivamente para as da área pedagógica, sobretudo para o ensino de Didática, Prática de Ensino e Psicologia da Educação. O diferencial da Fafing estava na inexistência de uma Faculdade de Educação na sua estrutura, presente na maioria das Universidades brasileiras, possibilitando que a formação se desse integralmente no interior de cada curso. Esse desenho institucional consistiu em um traço particular do curso de História em Porto Nacional, composto por professores que atuavam na parte específica e nas disciplinas 
pedagógicas, promovendo a formação integral do futuro profissional de História.

A eliminação do núcleo básico referente aos Estudos Sociais tornou possível a expansão dos conteúdos programáticos específicos da História. A chegada dos primeiros historiadores, com efeito, influenciou na melhoria geral da organização das disciplinas. Mas é importante destacar que essa nova composição de professores parece ter dado início, igualmente, ao estabelecimento de um campo marcado pelo prestígio de determinadas disciplinas em detrimento de outras. O exemplo maior fica por conta de História Antiga, História Medieval e História Contemporânea, que passaram para 120 horas cada uma, ao passo que História Moderna ficou com 'apenas' 60 horas. Cabe registrar também a permanência da disciplina Geografia e o fato de o primeiro ano ter ficado quase todo dedicado às 'complementares' ao ensino de História, normalmente justificadas por sua contribuição para formar uma sólida base humanista nos discentes, como é o caso da Sociologia e da Filosofia.

Em 1988, mesmo ano em que se formou a primeira turma de História da Fafing, foi criado o estado do Tocantins. ${ }^{19} \mathrm{Um}$ ano depois, o censo educacional revelou um significativo percentual de professores da rede básica de ensino sem curso superior no mais novo estado da Federação.

Foi nesse contexto que aconteceu a segunda reformulação curricular do curso de História em Porto Nacional, inspirada especialmente no currículo da UFG. Essa nova Estrutura se distanciava das duas anteriores (1985 e 1987), caracterizadas por uma orientação essencialmente voltada para a formação de professores, sob a justificativa de "adequação à realidade da instituição" e para "privilegiar com maior carga horária as disciplinas nucleares, específicas do curso". Por um lado, esse currículo reorientado lançou bases para alicerçar o curso com disciplinas que favoreciam a formação de profissionais mais bem preparados em termos de conhecimentos históricos, mas por outro lado deixou em aberto a problemática que se faria presente nas discussões curriculares durante toda a década de 1990: como conciliar uma formação sólida tanto em conteúdos como nas ferramentas necessárias ao exercício da docência? Em outras palavras, como estruturar no currículo as orientações de um curso voltado para o ensino de primeiro e segundo graus e para a pesquisa histórica? Essas indagações seriam o fio condutor das discussões em torno do perfil do 
curso de História durante toda a década de 1990, não apenas em Porto Nacional, mas em todo o país.

Em 1991 a Fafing foi encampada pela Universidade do Tocantins, instituição recém-criada pelo governo estadual. Nesse novo contexto, foram redefinidos os mecanismos de contratação de novos professores. Se até aquele momento a principal estratégia havia sido arregimentar pessoas que tinham ligação com a cidade, notadamente portuenses que haviam saído para se graduar em outros estados, daí em diante passou-se a priorizar a contratação de historiadores que já estivessem, ao menos, ingressados em Programas de PósGraduação Stricto Sensu. ${ }^{20}$

Contudo, essa qualificação docente também teve um efeito contrário à melhoria do curso, pois em função da instabilidade institucional, vários professores que concluíam o mestrado acabavam deixando a Universidade, rumando para outras regiões do país. Para repor essas vagas continuaram chegando a Porto Nacional novos professores. Uma comparação do quadro de professores revela que se durante os primeiros anos de funcionamento do curso a Universidade Federal de Goiás consistiu na principal instituição formadora do quadro docente, o perfil dos mestres que foram chegando no transcorrer da década era notadamente caracterizado por jovens que vinham de diferentes instituições, tais como UFMG, USP, Unicamp, UFRJ e Unesp, procurando o Tocantins em busca de uma primeira oportunidade de lecionar no ensino superior.

Esses novos professores historiadores realizaram cursos de graduação em uma mesma época, embora em diferentes instituições: meados dos anos 1980. Além dos significados para a formação política, aquele momento também foi importante quando se considera que a abertura política favoreceu o surgimento de um contexto em que o mercado editorial foi significativamente ampliado pelas publicações estrangeiras. Essa situação permitiu a intensificação do processo de 'revisionismo historiográfico' em curso desde o final dos anos 1970, possibilitado pela entrada no Brasil de um número cada vez maior de livros, sobretudo franceses e ingleses, que traziam novas abordagens sobre a história. Esse processo contribuiu em diferentes sentidos para a historiografia brasileira, como se observa na criação da Anpuh, na ampliação dos cursos de pós-graduação, na organização de centros de documentação, na realização de eventos nacionais, nas lutas pela revisão da legislação federal relativa ao ensino de 
história e nas alterações no currículo para expugnar as heranças do período anterior e se adequar às novas mudanças, dando um novo sentido para a formação e atuação do historiador no Brasil.

Como momento de rupturas, de transição e permanências em todos os sentidos, o conflito de gerações e filiações teóricas foi algo inerente ao contexto em que foram formados os professores do curso de História em Porto Nacional. Formaram-se em um momento em que na historiografia brasileira as abordagens marxistas às vezes associadas à militância política, característica do período ditatorial, dividiram espaço com outras vertentes da história. Por isso, é possível afirmar que os historiadores que tiveram sua formação teórica e acadêmica naquela atmosfera gerada entre meados da década de 1980 e início dos anos 1990 vivenciaram um marco para o ensino superior de História e para a historiografia no país. Em decorrência disso, ao chegarem a Porto Nacional, esses jovens traziam em suas bagagens não apenas titulação, mas um conjunto de novos referenciais teóricos, temáticas de pesquisas, abordagens metodológicas e estratégias de ensino.

As ementas e o corpo da bibliografia básica, que foi sendo constituída e reconstituída, sinalizam as concepções de história que orientavam os professores. Suas opções teóricas pareciam extrapolar o sentido de 'referencial teórico' das dissertações, influenciando nas proposições e redefinições da modelagem do curso, transformando o espaço acadêmico com a implantação de núcleos de pesquisas e a inserção de disciplinas optativas ligadas aos seus objetos de pesquisas, com destaque para as questões de gênero, as relações étnicas, os estudos indígenas e da história do cotidiano. Vários desses docentes, ao chegarem a Porto Nacional, rapidamente identificaram um rico campo de pesquisa praticamente inexplorado, pois o Norte não havia sido suficientemente estudado pelos historiadores goianos até 1988, salvo em alguns poucos trabalhos relacionados ao 'ciclo da mineração' e à questão do coronelismo, além de pesquisas referentes aos povos indígenas. As conversas com os alunos em sala de aula, sobre temas relacionados à criação do Tocantins, estimulavam os professores a tomar problemáticas locais como objetos de estudo e a identificar alguns discentes interessados pela pesquisa histórica. Esse aspecto se associava à demanda social existente em torno da elaboração de uma história regional colocada pela mídia como necessária à construção da identidade dos tocantinenses. 
Por isso, em 1997 os professores elaboraram uma nova Proposta Pedagógica para o curso, que trouxe pela primeira vez a intenção oficial de implementação do bacharelado. Ora, se as Estruturas Curriculares formuladas a partir de 1987 foram sendo aperfeiçoadas com componentes que associavam formação pedagógica e orientação para a pesquisa, por que haveria então a necessidade de se promover a diferenciação entre bacharelado e licenciatura? Um olhar sobre o cenário nacional da época permite inferir que essa proposta era uma tentativa local de se antecipar às exigências da nova Lei de Diretrizes e Bases da Educação Nacional, 9.394/96 (LDBEN) e aos Pareceres do Conselho Nacional de Educação, que orientaram os cursos de licenciatura a se voltarem para a efetiva formação de professores, cujas 'competências e habilidades' deveriam ser alicerçadas em conhecimentos quase que exclusivos da área pedagógica.

Apesar dos argumentos apresentados, sinalizando que o campo de trabalho para o profissional de história não se limitava às atividades de docência, a proposição do bacharelado não foi aceita pela direção da Universidade do Tocantins. A alternativa encontrada pelos professores, mais uma vez, foi a manutenção de um currículo misto, envolvendo o preparo dos alunos para a docência e para a pesquisa, o que culminou com a implantação em 1998 de uma Estrutura semestral, em substituição ao antigo regime anual.

Mas as pressões institucionais sobre o curso de História continuaram ocorrendo. O dispositivo da LDBEN de 1996 que estabeleceu, em seu art. 62, que "a formação de docentes para atuar na educação básica far-se-á em nível superior, em curso de licenciatura, de graduação plena, em universidades e institutos superiores de educação..." provocou, em nível nacional, uma grande demanda por formação de professores. Instigadas pelos governos, muitas instituições de ensino superior criaram diversos cursos a distância, semipresenciais ou de curta duração. Nessas condições, possibilitar aos professores ferramentas para a pesquisa tornou-se uma questão secundária, na medida em que uma boa formação em conteúdos e metodologias já seria o suficiente possível. No âmbito regional foi criado o Programa de Formação de Professores em Regime Especial, parceria entre a Universidade do Tocantins e a Secretaria de Educação e Cultura do Estado, que exigiu do curso de História a elaboração de um novo currículo.

Nessa nova organização Sociologia e Filosofia ganharam o adjetivo 'da Educação', e Teoria do Currículo apareceu como novidade, justificada pelo 
imperativo de que os alunos deveriam conhecer as questões que envolvem o complexo processo de seleção dos saberes a serem ensinados. Associada a essa disciplina, a de Tecnologias Educacionais propunha desenvolver conteúdos relacionados aos recursos tecnológicos e sua relação com a aprendizagem. Até o quinto período o docente especialista deveria trabalhar as noções gerais e teóricas sobre o ensino de história na Educação Básica, e a partir do sexto a disciplina deveria ser ministrada por um pedagogo, visando introduzir o aluno nas atividades de estágio propriamente ditas.

Os Tópicos em História apareceram sob a justificativa de associar o conteúdo histórico constante na Estrutura Curricular às temáticas dos Parâmetros Curriculares Nacionais (PCNs) do Ensino Fundamental e Médio. A título de exemplo, citam-se as disciplinas Metodologia do Ensino em História, História da Arte, História Indígena, História da Escravidão na América, História e Literatura e História e Cinema, além de Ciências Políticas. Na mesma direção, os Tópicos Interdisciplinares deveriam ser orientados por temas e/ou conteúdos que possibilitassem ao discente a construção e socialização dos conhecimentos de forma holística. Como exemplo, a Proposta Pedagógica do curso de Regime Especial cita as possibilidades de se trabalhar conjuntamente GeoHistória, Cartografia, Ética e Cidadania, Ecologia e Meio Ambiente, Educação Sexual, Religião e Religiosidades.

Essa Estrutura Curricular introduziu, pela primeira vez, a disciplina Historiografia do Brasil, com uma abordagem sobre os marcos, as categorias de análises, o instrumental teórico e a contextualização dos quadros da produção do conhecimento histórico do Brasil. Ao mesmo tempo, houve a substituição na nomenclatura de História Regional por História do Tocantins, numa clara manifestação de que fossem privilegiadas, na formação dos alunos, algumas temáticas sobre o passado do antigo Norte Goiano.

Os resultados numéricos desse Programa de Formação em Regime Especial foram realmente expressivos e certamente contribuíram decisivamente para que o Tocantins superasse o alto índice de professores sem habilitação mínima lecionando na educação básica. Sem uma política dessa natureza, provavelmente seriam necessárias décadas para formar tantos professores. Era a realização do sonho de Ruy Rodrigues da Silva, mentor da Fafing.

Contudo, ainda não é possível avaliar os impactos dessa orientação pedagógica nas experiências construídas ao longo dos anos 1990, quando jovens 
professores do curso de História, em Porto Nacional, procuraram construir um currículo que formasse o profissional de história integralmente.

\section{CONSIDERAÇÕES FINAIS}

A criação da Faculdade de Filosofia do Norte Goiano, na cidade de Porto Nacional, teve um grande impacto no ensino de História na região central do Brasil, ainda nos anos 1980. O perfil do seu alunado sobressaía-se como uma das principais características da identidade da Instituição. Vários desses alunos tinham de percorrer distâncias significativas, em meios de transporte nada adequados, para poder chegar todos os dias a tempo de assistir às aulas. Outros eram profissionais da educação que havia anos se encontravam no exercício da docência, para os quais o diploma de nível superior consistia na realização de um sonho - distante até então, para muitos. Acrescente-se a possibilidade de conseguirem uma aposentadoria com remuneração mais digna.

Além disso, a despeito das adversidades, as estratégias criadas pelos professores possibilitaram que a década de 1990 fosse marcada por avanços no interior do curso de História, quando encampado pela Universidade do Tocantins. Embora não se tenha conseguido estabelecer, por longo período, um padrão que equilibrasse conhecimentos históricos e pedagógicos, as experiências se mostraram válidas quando comparadas com as tensões existentes no debate nacional em torno do ensino de história. Para tanto, além dos esforços empreendidos pelos pioneiros, contribuíram sobremaneira a chegada de um conjunto de novos professores, os quais buscaram introduzir no curso novas concepções teóricas, possibilitando a formação de um incipiente campo de pesquisa, e o contato dos estudantes com novas temáticas e abordagens teóricas que diversificaram o campo de estudo.

O Tocantins deixou de ser o único estado do Brasil que não possuía uma instituição federal de ensino superior em 23 de outubro de 2000, quando o Ministério da Educação criou a Universidade Federal do Tocantins (UFT). Essa nova instituição recebeu, a partir de junho de 2002, a transferência de parte dos bens patrimoniais da Universidade do Tocantins, além dos alunos e cursos regulares, entre eles o de História, que vivenciaria mais de perto as perspectivas e os dilemas dos cursos congêneres em nível nacional. 


\section{NOTAS}

${ }^{1}$ FERREIRA, Marieta de Moraes. Notas sobre a institucionalização dos cursos universitários de História no Rio de Janeiro. In: SALGADO, Manoel (Org.). Estudos sobre a escrita da história. Rio de Janeiro: 7 Letras, 2006. p.145-151.

${ }^{2}$ ROIZ, Diogo da Silva. A institucionalização do ensino universitário de história na faculdade de filosofia, ciências e letras da Universidade de São Paulo, 1934-1956. Dissertação (Mestrado em História) - Faculdade de Ciências Humanas e Sociais da Universidade Estadual Paulista. Franca (SP), 2004; além dessa Dissertação, cabe destacar as referências encontradas em CAPELATO, Maria Helena Rolim et al. Escola Uspiana de História. In: Revista de Estudos Avançados, São Paulo: Instituto de Estudos Avançados (IEA), textos online, 2005; EVANGELISTA, O. Formar o mestre na universidade: a experiência paulista nos anos de 1930. Educ. Pesqui., São Paulo, v.27, n.2, dez. 2001.

${ }^{3}$ BENJAMIN, Walter. Rua de mão única. v.2. Obras escolhidas. São Paulo: Brasiliense, 1995.

${ }^{4}$ Natural de Porto Nacional, Ruy Rodrigues da Silva formou-se em Filosofia, em Belo Horizonte, e em Teologia, no Rio de Janeiro, onde se ordenou padre na década de 1950. Ao deixar as atividades sacerdotais mudou-se no início da década de 1960 para Goiânia, onde passou a lecionar na UFG.

${ }^{5}$ SILVA, Ruy Rodrigues. Exercícios de admiração: reflexões sobre pessoas, poder, cultura e cidades. Goiânia: Kelps, 2009. p.43.

${ }^{6}$ Goiás possuía na época uma extensão territorial bastante significativa. Segundo Ruy Rodrigues, não raras vezes essa fiscalização por parte da Secretaria tinha de ser realizada com viagens em aviões, em função das distâncias e da precariedade das estradas.

${ }^{7}$ Cf. SANTOS, Jocyléia Santana dos. O sonho de uma geração: movimento estudantil em Goiás e Tocantins. Goiânia: UCG, 2007.

${ }^{8}$ A participação do Ministério da Educação e Cultura, que era de 10,6\% em 1965, decresceu para 4,3\% em 1975 e manteve-se na média de 5,5\% até 1983. Contraditoriamente, essa redução ocorria precisamente em um momento no qual a Reforma Universitária de 1968 preconizava o aumento de matrículas no ensino superior. GERMANO, José Willington. Estado militar e educação no Brasil (1964-1985). São Paulo: Cortez, 1993.

${ }^{9}$ TANURI, Leonor Maria. História da formação de professores. Revista Brasileira de Educação, São Paulo: Anped, n.14, p.61-88, maio-ago. 2000.

${ }_{10}$ TEIXEIRA, Maria Dulce Loyola. Mauro Borges e a crise político-militar de $1961 \mathrm{em}$ Goiás: movimento da legalidade. Brasília: Ed. Senado Federal, 1994.

${ }^{11}$ SALLES, Antônio Pinheiro. A Ditadura Militar em Goiás. Goiânia: Kelps, 2008.

${ }^{12} \mathrm{O}$ seu exílio durou 25 anos, morando a maior parte do tempo em Paris, onde também se formou em Sociologia. Ao retornar ao Brasil, após a Lei de Anistia, voltou para Porto Nacional. Após a criação do estado de Tocantins, foi secretário da Educação e secretário ex- 
traordinário da Ciência e Tecnologia. Em 1999, foi nomeado Reitor da Universidade do Tocantins.

${ }^{13}$ CASSIMIRO, Maria do Rosário; GONÇALVES, Oliveira Leite. Rumos da universidade brasileira. Goiânia: UFG, 1986. Cf. BRASIL. Ministério da Educação. Expansão do ensino superior em Goiás. Goiânia: Demec-GO,1986.

${ }^{14}$ FAFING se prepara para o seu primeiro vestibular: expectativa da Secretaria de Educação é positiva. O Estado do Tocantins, 5 a 10 abr. 1985.

${ }^{15}$ Em 1982 foi realizado o Primeiro Encontro Perspectivas do Ensino de História, na USP, com a presença de pesquisadores e professores do ensino de $1^{\circ} \mathrm{e} 2^{\circ}$ Graus. A partir dele foram criados outros eventos voltados para essa temática, como os Encontros de Pesquisadores do Ensino de História. Cf. CERRI, Luis Fernando. Ensino da História: fronteiras interdisciplinares, avanços e problemas. Caderno de História, Uberlândia (MG), v.1, n.12/13, p.7-21, 2004/2005.

${ }^{16}$ A criação dos cursos de Estudos Sociais ocorreu, sobretudo, nas faculdades privadas. Embora isso não tenha significado o fim dos cursos de História nas Universidades, egressos de ambos os cursos tiveram de concorrer às mesmas vagas oferecidas para a docência entre a $5^{\mathrm{a}}$ e a $8^{\mathrm{a}}$ séries. A partir de 1976, no entanto, com a tentativa oficial de se restringir o ensino dessas séries somente para os oriundos das licenciaturas curtas em Estudos Sociais, passou a haver uma mobilização efetiva dos profissionais de História na defesa do seu mercado de trabalho.

${ }^{17} \mathrm{O}$ currículo mínimo do curso de ES havia sido estabelecido pelo Parecer do Conselho Federal de Educação 106/66, que definia como disciplinas obrigatórias: História: Antiga, Medieval, Moderna, Contemporânea, do Brasil (incluindo Organização Política e Social do Brasil); Geografia: elementos da Geografia Física, Geografia Humana e Geografia do Brasil, e Fundamentos das Ciências Sociais.

${ }^{18}$ Cabe destacar que o modelo que historicamente predominou nas Universidades brasileiras foi o que se iniciou nos anos 1930 na USP, onde as Faculdades de Educação e de Filosofia atuavam separadamente. Nesse caso, a formação específica oferecida pela Faculdade de Filosofia precisava ser complementada com as disciplinas do curso de licenciatura, ministradas pela Faculdade de Educação.

${ }^{19} \mathrm{O}$ Estado do Tocantins foi criado pela Constituição Federal de 1988, que desmembrou as regiões norte e sul de Goiás. Pela nova divisão territorial o antigo Norte Goiano passou a se chamar Tocantins.

${ }^{20}$ Além das iniciativas individuais que cada professor empreendeu para realizar seus cursos de mestrado ou doutorado, organizou-se, pelo que se tem registrado, o primeiro Projeto de Mestrado Interinstitucional no Brasil, entre a Universidade do Tocantins e a Universidade Federal de Pernambuco, com a participação do CNPq.

Artigo recebido em 20 de dezembro de 2012. Aprovado em 14 de abril de 2013. 